\title{
Prediction of weight and percentage of salable meat from Brazilian market lambs by subjective conformation and fatness scores
}

\author{
Hélio de Almeida Ricardo', Roberto de Oliveira Roça ${ }^{2}$, Nicola Ross Lambe ${ }^{3}$, Leonardo de \\ Oliveira Seno ${ }^{4}$, Ingrid Harumi de Souza Fuzikawa ${ }^{5}$, Alexandre Rodrigo Mendes Fernandes ${ }^{4}$
}

\footnotetext{
${ }^{1}$ Universidade Estadual Paulista "Júlio de Mesquita Filho", Faculdade de Medicina Veterinária e Zootecnia, Departamento de Produção Animal, Botucatu, SP, Brazil.

2 Universidade Estadual Paulista "Júlio de Mesquita Filho", Faculdade de Ciências Agronômicas, Departamento de Economia, Sociologia e Tecnologia, Botucatu, SP, Brazil.

${ }^{3}$ Scotland's Rural College, Animal and Veterinary Sciences, Kirkton Farm, Crianlarich, Scotland, UK.

${ }^{4}$ Universidade Federal da Grande Dourados, Faculdade de Ciências Agrárias, Dourados, MS, Brazil.

${ }^{5}$ Universidade de São Paulo, Faculdade de Zootecnia e Engenharia de Alimentos, Departamento de Zootecnia, Pirassununga, SP, Brazil.
}

\begin{abstract}
This study assessed the use of conformation and fatness scores of the EUROP sheep carcass grading system to predict weight and percentage of salable meat from Brazilian market lambs. Data were collected from in vivo, carcass, and retail production from 252 uncastrated lambs. Evaluated models included single regressions, two multivariate models, and one determined by the stepwise procedure. Conformation was moderately correlated with weight of salable meat. Fatness scores were correlated with rump perimeter, carcass width, and thoracic depth with coefficients of $-0.33,-0.32$, and -0.23 , respectively. Body weight was the best single predictor for weight of salable meat and cold carcass yield for percentage of salable meat. All multivariate models for weight of salable meat prediction were significant. Stepwise regression with body weight, leg perimeter, thoracic depth, rump perimeter, and fatness scores predicted $98 \%$ of weight of salable meat variation. For percentage of salable meat prediction, stepwise regression with cold carcass yield, leg perimeter, and conformation score was significant. The EUROP conformation and fatness scores can be used in Brazil for the prediction of lamb meat production.
\end{abstract}

Key Words: regression models, retail cuts, sheep

\section{Introduction}

Carcass grading system facilitates trade by the description of the most important commercial traits, directs products for appropriate niche markets, helps marketing, and is used as a public policy tool to regulate the sector (Price, 1995).

Muscularity and fatness are carcass traits used as basis for grading systems, evaluated subjectively or objectively, which have great impact on the carcass value. Muscularity indicates the amount of muscle tissue, determined by conformation or muscle to bone ratio and fatness describes the external and internal deposition of fat in the carcass.

Despite showing weak relationship with the weight and percentage of salable meat, subjective carcass assessment, for conformation and fatness, is considered important for both farmers and industry (Nsoso et al., 2000) and is used in various grading systems.

Received March 15, 2016 and accepted August 4, 2016

Corresponding author: helioar@zootecnista.com.br

http://dx.doi.org/10.1590/S1806-92902016001000010

Copyright (c) 2016 Sociedade Brasileira de Zootecnia. This is an Open Access article distributed under the terms of the Creative Commons Attribution License (http://creativecommons.org/licenses/by/4.0/), which permits unrestricted use, distribution, and reproduction in any medium, provided the original work is properly cited.
Australia and New Zealand, accounting for $13 \%$ of world production and $68 \%$ of the exported volume of sheep meat (FAO, 2015), use automated methods, described by Stanford et al. (1998), which predict the ratio of muscle and fat in the carcass. However, similar to many EU countries, the United Kingdom, a traditional sheep producer, uses a subjective grading system based on conformation and fatness of the carcasses (AHDB Beef \& Lamb, 2012).

Automated methods for carcass grading are more elaborate, have higher accuracy, but are more expensive, and the use of the method is justified mainly by the volume produced. Subjective methods of grading are cheaper, quicker, and easier to apply, despite the lower accuracy (Stanford et al., 1998). Our objective was to assess if EUROP conformation and fatness scores can be used to predict retail cut production of Brazilian market lambs.

\section{Material and Methods}

The study was conducted in a commercial slaughterhouse registered in the Federal Inspection Service, located in São Paulo State. All procedures for handling and slaughter of animals in the company were conducted in accordance with the Regulation of Industrial and Sanitary Inspection of Animal Products in the country (Brasil, 1952) 
and Normative Instruction No. 56, of November 06, 2008, on the general procedures of Recommendations of Good Practices of Welfare for Farm Animals with Economic Interest, covering the production and transportation systems (Brasil, 2008).

The animals were evaluated pre-slaughter in the fasting area, held in the corral of the slaughterhouse, with 252 non-castrated male lambs chosen at random. Body weight (BW) was recorded with the use of a mobile mechanical scale with a capacity of $300 \mathrm{~kg}$ and body condition score (BCS) was determined according to the methodology described by Russell et al. (1969), scoring 0.5 of a score.

The slaughter procedure was performed following the steps of electrical stunning, bleeding, and removal of the head, feet, skin (and fleece), blood, digestive system, heart, lungs, liver, kidneys, and internal fat depots. After the slaughter, each carcass had its hot carcass weight (HCW) recorded, which was used to calculate the hot carcass yield $(\mathrm{HCY}=[\mathrm{HCW} \div \mathrm{BW}] \times 100)$. Cold carcass weight $(\mathrm{CCW})$ was recorded after chilling for $24 \mathrm{~h}$ at a temperature of $4{ }^{\circ} \mathrm{C}$ and was used to calculate the cold carcass yield $(\mathrm{CCY}=[\mathrm{CCW} \div \mathrm{BW}] \times 100)$ and chilling losses $(\mathrm{CL}=\{[\mathrm{HCW}-\mathrm{CCW}] \div \mathrm{HCW}\} \times 100)$.

In the cold carcass, linear measurements of carcass width (Wr), thoracic depth (Th), rump width (G), and rump perimeter (D) were determined as described by Carrasco et al. (2009), plus external carcass length (K, distance between the base of the neck and base of the tail from the back with a straight line) and leg perimeter (LP, maximum length around the leg).

Under the EU lamb carcass classification (EUROP) scheme (Commission Regulation (EC) No 823/98, 1998), each carcass was assessed and classified one hour after the slaughter. The classification of all carcasses was done subjectively by a trained technician. The carcass conformation scores (CS) describe the development of carcass profiles, particularly the essential components of the round, back, and shoulder. Under the EUROP system, five CS are defined, represented by the letters E, U, R, O, and $\mathrm{P}$. The letters represent an incremental scale ranging from $\mathrm{P}$, which denotes poor conformation, to $\mathrm{E}$, representing excellent conformation.

The carcass fatness scores (FS) describe the amount of fat on the outside of the carcass and in the thoracic cavity. Five scores are defined, represented by the numbers 1, 2, 3,4 , and 5. This incremental scale ranges from 1, which denotes low fatness, to 5 , denoting very high fatness. To be consistent with the statistical methods employed, CS scales were transformed to numerical classification units of 5 to 1 , with 5 representing score $\mathrm{E}$ and 1 representing score $\mathrm{P}$.
Retail cuts were based on New Zealand lamb carcass break-out (Beef + Lamb New Zealand Ltd., 2013): neck (NK, neck bone-in); shoulder (SH, shoulder banjo cut, bone-in); breast and flap (BF); loin (LO, loin with musculus longissimus lumborum bone-in between first and last lumbar vertebra); leg (LG, short cut leg, bone-in, chumpoff); frenched rack (FR, rack, fully frenched); shoulder rack (SR), and boneless chump (BL). Each trimmed cut was weighed and the data was used to determine the weight of salable meat (WSM) by: WSM, in $\mathrm{kg}=(\mathrm{NK}+\mathrm{SH}+\mathrm{BF}$ $+\mathrm{LO}+\mathrm{LG}+\mathrm{FR}+\mathrm{SR}+\mathrm{BL})$. With WSM, we determined the percentage of salable meat $(\mathrm{PSM}$, in $\%=[\mathrm{WSM} / \mathrm{BW}] \times 100)$.

Data analysis was performed with the aid of the statistical package R (R Development Core Team, 2012). Descriptive analysis was performed and the Spearman correlation coefficients (cor function, stats package, R Development Core Team, 2012), among all variables were determined. Simple linear regressions $(y=a+b x)$ and multiple regression analysis, among the variables collected in vivo and in the carcass (independent variables), and WSM and PSM (dependent variables) were assessed. For multiple regressions, three models were evaluated, one composed of $\mathrm{CS}+\mathrm{FS}$, another of $\mathrm{HCW}+\mathrm{CS}+\mathrm{FS}$, and the third obtained by the stepwise command ( $1 \mathrm{~m}$ and step functions, stats package, R Development Core Team, 2012). For all regressions, the coefficient of determination $\left(\mathrm{R}^{2}\right)$, the root mean square error (RMSE, rmse function, hydroGOF package, Zambrano-Bigarini, 2012), and the Akaike information criterion (AIC, AIC function, stats package, R Development Core Team, 2012) were determined.

$$
\text { R statistical coding for model fitting }
$$

\#Data input\#

ad <- read.table("C:/Estatisticas/R/dados2.txt", header=TRUE, dec=",")

\#Single regression\# sing_reg $<-\operatorname{lm}($ dependent variable $\sim$ independent variable, data $=$ ad) anova(sing_reg) summary.lm(sing_reg) coef $<$ - coefficients(sing_reg); coef $\mathrm{R} 2<-$ (cor(sing_reg\$fitted.values, ad\$dependent variable, method="pearson") ) 2 ; R2

rmse $<$ - rmse(sing_reg\$fitted.value, ad\$dependent variable,na.rm $=$ TRUE); rmse

CIA $<$ - step(sing_reg, direction="both")

\#Multiple regression\#

mult_reg $1<-\operatorname{lm}$ (dependent variable $\sim$ conformation + fatness, data $=\mathrm{ad}$ ) 
anova(mult_reg1)

summary.lm(mult_reg1)

coef $<$ - coefficients(mult_reg1); coef

R2 <- (cor(mult_reg1\$fitted.values, ad\$dependent

variable, method="pearson"))^2; R2

rmse $<$-rmse(mult_reg1\$fitted.value, ad\$dependent

variable,na.rm $=$ TRUE); rmse

CIA <- step(mult_reg1, direction="both")

mult_reg2 <- $\operatorname{lm}($ dependent variable $\sim \mathrm{HCW}+$

conformation + fatness, data $=\mathrm{ad})$

anova(mult_reg2)

summary.1m(mult_reg2)

coef $<$ - coefficients(mult_reg2); coef

R2 <- (cor(mult_reg2\$fitted.values, ad\$dependent

variable, method="pearson"))^2; R2

rmse <-rmse(mult_reg2\$fitted.value, ad\$dependent

variable,na.rm $=$ TRUE); rmse

CIA <- step(mult_reg2, direction="both")

mult_stpew $<-\operatorname{lm}($ dependente variable $\sim$ all independente

variables, data $=\mathrm{ad})$

teste $<$ - step(mult_stpew, direction="both")

stepw_sign $<-1 \mathrm{~lm}$ (dependent variable $\sim$ significant

independente variables, data $=\mathrm{ad}$ )

anova(stepw_sign)

summary.lm(stepw_sign)

\section{Results}

The average BW of the animals was $36.1 \mathrm{~kg}$ with a mean of 2.69 BCS. Carcasses had an average HCW of $17.77 \mathrm{~kg}$ with yield of $49.19 \%$. By the subjective assessment of the carcasses, mean scores of 2.41 and 1.59 were obtained for conformation and fatness, respectively. At the end of the manufacture of the cuts, an average WSM of $12.47 \mathrm{~kg}$ was obtained with $71.27 \%$ of PSM (Table 1).

The conformation scores were positively correlated with WSM, while there was no significant correlation between FS and WSM or PSM (Table 2). The carcass conformation showed moderate positive correlation coefficients with $\mathrm{BW}, \mathrm{HCW}, \mathrm{CCW}, \mathrm{CCY}$, and external carcass length $(\mathrm{K})$ and weak negative coefficients with rump width $(\mathrm{G})$ and rump perimeter (D).

The fatness scores showed only negative coefficients with $\mathrm{D}$, carcass width (Wr), and thoracic depth (Th). There was a strong correlation between WSM and BW, HCW, $\mathrm{CCW}, \mathrm{K}, \mathrm{D}$, Th, and leg perimeter (LP) and moderate coefficients with BCS and Wr. The yield of retail cuts had only significant negative correlations with $\mathrm{HCY}$ and $\mathrm{CCY}$ and positive with LP.
For WSM, significant regressions were obtained $(\mathrm{P}<0.01)$ with $\mathrm{BW}, \mathrm{HCW}, \mathrm{CS}, \mathrm{CCW}, \mathrm{K}, \mathrm{D}, \mathrm{Wr}, \mathrm{Th}$, and LP. The body weight was the best single predictor of WSM, with coefficient of determination of 0.95 , while CS had a value of 0.22 . Among the linear measures of the carcass, Th was the best predictor (Table 3). Only HCY, CCY, and LP showed significant results $(\mathrm{P}<0.05)$ for $\mathrm{PSM}$ prediction, with coefficients of $0.42,0.45$, and 0.19 , respectively (Table 4 ).

The three multivariate models for WSM prediction were significant $(\mathrm{P}<0.01)$, in which the stepwise analysis produced the model $\mathrm{WSM}=\mathrm{BW}+\mathrm{LP}+\mathrm{Th}+\mathrm{D}+\mathrm{FS}$. The model CS + FS accounted for $22 \%$ of WSM variation, with better results for $\mathrm{HCW}+\mathrm{CS}+\mathrm{FS}$ and the stepwise model, shown above, with 92 and $98 \%$ of variation explained, respectively (Table 5). For PSM, only the stepwise model $\mathrm{PSM}=\mathrm{CCY}+\mathrm{LP}+\mathrm{CS}$ explained a significant proportion of the variation $(\mathrm{P}<0.01)$.

\section{Discussion}

Body and carcass weight are the strongest single predictors and the most commonly used traits in prediction models of meat production for total production and yield or to predict the tissue composition of the carcass, or even meat quality traits, such as tenderness (Smith et al., 1969; Safari et al., 2001; Brady et al., 2003; Díaz et al., 2004; Lambe et al., 2009).

The results showed the importance of weight for lamb carcass grading systems, in which the main lambproducing countries, such as Australia, New Zealand,

Table 1 - Means, standard deviation (SD), and ranges of assessed traits

\begin{tabular}{lcrrrr}
\hline Item & Acronym & Mean & SD & Minimum & Maximum \\
\hline Body weight, kg & BW & 36.11 & 7.62 & 26.80 & 55.00 \\
Body condition score & BCS & 2.69 & 0.88 & 2.00 & 5.00 \\
Hot carcass weight, kg & HCW & 17.77 & 3.93 & 13.10 & 27.50 \\
Hot carcass yield, \% & HCY & 49.19 & 2.56 & 46.03 & 59.64 \\
Conformation score & CS & 2.41 & 0.78 & 1.00 & 4.00 \\
Fatness score & FS & 1.59 & 0.57 & 1.00 & 3.00 \\
Cold carcass & CCW & 17.48 & 3.83 & 12.90 & 26.70 \\
weight, kg & & & & & \\
Cold carcass yield, \% & CCY & 48.39 & 2.59 & 45.34 & 58.93 \\
Chilling losses, \% & CL & 1.64 & 0.87 & 0.52 & 3.27 \\
External carcass & K & 61.45 & 7.60 & 45.00 & 79.00 \\
length, cm & & & & & \\
Rump width, cm & G & 14.00 & 4.04 & 11.00 & 24.00 \\
Rump perimeter, cm & D & 60.24 & 3.89 & 54.00 & 70.00 \\
Carcass width, cm & Wr & 20.90 & 1.86 & 17.00 & 26.00 \\
Thoracic depth, cm & Th & 26.24 & 1.98 & 23.00 & 30.00 \\
Leg perimeter, cm & LP & 36.62 & 2.85 & 32.00 & 44.00 \\
Weight of salable & WSM & 12.47 & 2.93 & 8.17 & 19.99 \\
meat, kg & & & & & \\
Percentage of salable & PSM & 71.27 & 4.71 & 49.52 & 75.69 \\
meal, \% & & & & & \\
\hline & & & & &
\end{tabular}


Table 2 - Significant Spearman correlation coefficients $(\mathrm{P}<0.05)$ among animal, carcass traits, and meat production

\begin{tabular}{|c|c|c|c|c|c|c|c|c|c|c|c|c|c|c|c|c|}
\hline Item & $\mathrm{CS}$ & FS & BW & BCS & HCW & HCY & $\mathrm{CCW}$ & $\mathrm{CCY}$ & $\mathrm{CL}$ & $\mathrm{K}$ & $\mathrm{G}$ & $\mathrm{D}$ & $\mathrm{Wr}$ & Th & LP & WSM \\
\hline \multicolumn{17}{|l|}{ FS } \\
\hline BW & 0.50 & & & & & & & & & & & & & & & \\
\hline BCS & & & 0.35 & & & & & & & & & & & & & \\
\hline $\mathrm{HCY}$ & & & -0.29 & -0.25 & 0.42 & & & & & & & & & & & \\
\hline $\mathrm{CCW}$ & 0.59 & & 0.91 & 0.29 & 0.99 & 0.34 & & & & & & & & & & \\
\hline $\mathrm{CCY}$ & 0.47 & & & & 0.33 & 0.98 & 0.35 & & & & & & & & & \\
\hline G & -0.23 & & & & -0.26 & & & & 0.34 & -0.40 & & & & & & \\
\hline D & -0.26 & -0.33 & 0.20 & 0.24 & 0.49 & & 0.61 & & & -0.15 & 0.30 & & & & & \\
\hline $\mathrm{Wr}$ & & -0.31 & 0.30 & 0.27 & 0.25 & & 0.29 & & & & 0.33 & 0.92 & & & & \\
\hline Th & & -0.23 & 0.68 & 0.23 & 0.61 & & 0.73 & & & 0.53 & & 0.40 & 0.42 & & & \\
\hline LP & & & 0.67 & 0.23 & 0.55 & & 0.69 & & & 0.48 & & 0.29 & 0.35 & 0.54 & & \\
\hline WSM & 0.55 & & 0.98 & 0.39 & 0.96 & & 0.96 & & & 0.80 & & 0.80 & 0.53 & 0.85 & 0.81 & \\
\hline
\end{tabular}

CS - conformation score; FS - fatness score; BW - body weight (kg); BCS - body condition score; HCW - hot carcass weight (kg); HCY - hot carcass yield (\%); CCW - cold carcass weight $(\mathrm{kg})$; CCY - cold carcass yield (\%); CL - chilling losses (\%); K - external carcass length (cm); G - rump width (cm); D - rump perimeter (cm); Wr - carcass width (cm); Th - thoracic depth $(\mathrm{cm})$; LP - leg perimeter $(\mathrm{cm})$; WSM - weight of salable meat $(\mathrm{kg})$; PSM - percentage of salable meat $(\%)$.

Table 3 - Single regression equations to predict weight of salable meat (WSM)

\begin{tabular}{|c|c|c|c|c|c|c|c|}
\hline Dependent variable & Independent variable & $\mathrm{a}$ & $\mathrm{b}$ & $\mathrm{R}^{2}$ & RMSE & AIC & P-value \\
\hline \multirow[t]{15}{*}{ WSM } & BW & -1.0529 & 0.3744 & 0.9511 & 0.6591 & -22.2548 & $<0.0001$ \\
\hline & BCS & 9.6128 & 1.0608 & 0.1020 & 2.8230 & 62.1192 & 0.0913 \\
\hline & HCW & -0.2986 & 0.7182 & 0.9308 & 0.7836 & -12.2120 & $<0.0001$ \\
\hline & $\mathrm{HCY}$ & 8.0202 & 0.0904 & 0.0063 & 2.9695 & 65.0551 & 0.6829 \\
\hline & $\mathrm{CS}$ & 8.2083 & 1.7639 & 0.2212 & 2.6288 & 57.9870 & 0.0100 \\
\hline & FS & 12.0030 & 0.2919 & 0.0032 & 2.9741 & 65.1443 & 0.7702 \\
\hline & $\mathrm{CCW}$ & -0.3893 & 0.7356 & 0.9267 & 0.0863 & -10.5585 & $<0.0001$ \\
\hline & $\mathrm{CCY}$ & 9.9214 & 0.0526 & 0.0022 & 2.9757 & 65.1749 & 0.8107 \\
\hline & CL & 11.4737 & 0.6054 & 0.0325 & 2.9300 & 64.2786 & 0.3491 \\
\hline & $\mathrm{K}$ & -6.4926 & 0.3085 & 0.6425 & 1.7811 & 35.4069 & $<0.0001$ \\
\hline & G & 15.1593 & -0.1924 & 0.0704 & 2.8721 & 63.1194 & 0.1641 \\
\hline & $\mathrm{D}$ & -22.3569 & 0.5781 & 0.5904 & 1.9065 & 39.3547 & $<0.0001$ \\
\hline & $\mathrm{Wr}$ & -3.0866 & 0.7443 & 0.2235 & 2.6249 & 57.9001 & 0.0096 \\
\hline & $\mathrm{Th}$ & -20.7582 & 1.2661 & 0.7313 & 1.5440 & 27.1218 & $<0.0001$ \\
\hline & LP & -17.1388 & 0.8084 & 0.6187 & 1.8394 & 37.2752 & $<0.0001$ \\
\hline
\end{tabular}

a - intercept; b - regression coefficient; $\mathrm{R}^{2}$ - coefficient of determination; RMSE - root mean square error; AIC - Akaike information criterion; WSM - weight of salable meat (kg); BW - body weight (kg); BCS - body condition score; HCW - hot carcass weight (kg); HCY - hot carcass yield (\%); CS - conformation score; FS - fatness score; CCW - cold carcass weight (kg); CCY - cold carcass yield (\%); CL - chilling losses (\%); K - external carcass length (cm); G - rump width (cm); D - rump perimeter (cm); Wr - carcass width (cm); Th - thoracic depth $(\mathrm{cm})$; LP - leg perimeter $(\mathrm{cm})$.

Table 4 - Single regression equations to predict percentage of salable meat (PSM)

\begin{tabular}{|c|c|c|c|c|c|c|c|}
\hline Dependent variable & Independent variable & $\mathrm{a}$ & $\mathrm{b}$ & $\mathrm{R}^{2}$ & RMSE & $\mathrm{AIC}$ & P-value \\
\hline \multirow[t]{15}{*}{ PSM } & BW & 67.2776 & 0.1106 & 0.0320 & 4.4220 & 91.9572 & 0.3532 \\
\hline & $\mathrm{BCS}$ & 68.4137 & 1.0630 & 0.0394 & 4.7038 & 91.7335 & 0.3017 \\
\hline & HCW & 70.0539 & 0.0686 & 0.0033 & 4.7916 & 92.8054 & 0.7683 \\
\hline & $\mathrm{HCY}$ & 129.9376 & -1.1925 & 0.4209 & 3.6522 & 77.0571 & 0.0001 \\
\hline & $\mathrm{CS}$ & 74.4790 & -1.3283 & 0.0483 & 4.6820 & 91.4640 & 0.2519 \\
\hline & FS & 69.9733 & 0.8193 & 0.0098 & 4.7760 & 92.6162 & 0.6103 \\
\hline & CCW & 70.2505 & 0.0585 & 0.0023 & 4.7940 & 92.8348 & 0.8066 \\
\hline & $\mathrm{CCY}$ & 130.6841 & -1.2278 & 0.4538 & 3.5469 & 75.3601 & $<0.0001$ \\
\hline & $\mathrm{CL}$ & 69.2125 & 1.2570 & 0.0540 & 4.6680 & 91.2898 & 0.2250 \\
\hline & K & 67.0947 & 0.0680 & 0.0120 & 4.7705 & 92.5496 & 0.5713 \\
\hline & $\mathrm{G}$ & 68.1737 & 0.2214 & 0.0359 & 4.7124 & 91.8392 & 0.3247 \\
\hline & D & 48.6703 & 0.3752 & 0.0958 & 4.5637 & 89.9794 & 0.1023 \\
\hline & $\mathrm{Wr}$ & 62.0324 & 0.4422 & 0.0304 & 4.7259 & 92.0051 & 0.3657 \\
\hline & Th & 59.6249 & 0.4439 & 0.0346 & 4.7159 & 91.8783 & 0.3338 \\
\hline & LP & 44.6060 & 0.7282 & 0.1934 & 4.3104 & 86.6677 & 0.0170 \\
\hline
\end{tabular}

a - intercept; b - regression coefficient; $\mathrm{R}^{2}$ - coefficient of determination; RMSE - root mean square error; AIC - Akaike information criterion; PSM - percentage of salable meat (\%); BW - body weight (kg); BCS - body condition score; HCW - hot carcass weight (kg); HCY - hot carcass yield (\%); CS - conformation score; FS - fatness score; CCW - cold carcass weight $(\mathrm{kg})$; CCY - cold carcass yield (\%); CL - chilling losses (\%); K - external carcass length (cm); G - rump width (cm); D - rump perimeter (cm); Wr - carcass width (cm); Th - thoracic depth $(\mathrm{cm})$; LP - leg perimeter $(\mathrm{cm})$. 
Table 5 - Multiple regression equations to predict weight and percentage of salable meat

\begin{tabular}{|c|c|c|c|c|c|c|c|c|c|c|c|}
\hline $\begin{array}{l}\text { Dependent } \\
\text { variable }\end{array}$ & $\begin{array}{c}\text { Independent } \\
\text { variable }\end{array}$ & $\mathrm{a}$ & $\mathrm{b}_{1}$ & $\mathrm{~b}_{2}$ & $\mathrm{~b}_{3}$ & $\mathrm{~b}_{4}$ & $\mathrm{~b}_{5}$ & $\mathrm{R}^{2}$ & RMSE & AIC & P-value \\
\hline \multirow[t]{2}{*}{ WSM } & $\mathrm{CS}+\mathrm{FS}$ & 7.1082 & 2.1144 & 0.2452 & & & & 0.3035 & 2.7540 & 63.6220 & 0.0076 \\
\hline & $\mathrm{HCW}+\mathrm{CS}+\mathrm{FS}$ & 0.9641 & 0.6771 & -0.3280 & 0.1165 & & & 0.9236 & 0.9296 & -0.6756 & $<0.0001$ \\
\hline \multirow[t]{2}{*}{ PSM } & $\mathrm{CS}+\mathrm{FS}$ & 73.0773 & -1.3831 & 0.9671 & & & & 0.0618 & 4.7372 & 93.0495 & 0.4362 \\
\hline & $\mathrm{HCW}+\mathrm{CS}+\mathrm{FS}$ & 69.5678 & 0.3116 & -2.2514 & 1.0092 & & & 0.1088 & 4.7086 & 93.5606 & 0.4017 \\
\hline
\end{tabular}

$\mathrm{a}$ - intercept; $\mathrm{b}_{1}, \mathrm{~b}_{2}, \mathrm{~b}_{3}, \mathrm{~b}_{4}$, and $\mathrm{b}_{5}$ - regression coefficient; $\mathrm{R}^{2}$ - coefficient of determination; RMSE - root mean square error; AIC - Akaike information criterion; WSM - weight of salable meat (kg); PSM - percentage of salable meat (\%); BW - body weight (kg); BCS - body condition score; HCW - hot carcass weight (kg); HCY - hot carcass yield (\%); CS - conformation score; FS - fatness score; CCW - cold carcass weight (kg); CCY - cold carcass yield (\%); CL - chilling losses (\%); K - external carcass length (cm); G - rump width $(\mathrm{cm})$; D - rump perimeter $(\mathrm{cm})$; Wr - carcass width $(\mathrm{cm})$; Th - thoracic depth $(\mathrm{cm})$; LP - leg perimeter $(\mathrm{cm})$.

and the European Union, use hot or cold carcass weight to determine the price, which helps marketing. According to Price (1995), the reason for using weight as a grading criterion is the standardization of the production, which facilitates the processing of carcasses, manufacture, and packaging of the cuts.

Although Brazil has an important global market share of animal protein in the areas of beef, pork, and poultry (Ferraz and Felício, 2010), the Brazilian sheep industry has low international market share, accounting for only $1.0 \%$ of total production. The insignificance of the sector, even to the domestic market, means that there is little, if any, investment in technologies for carcass grading or prediction of the carcass yield.

Officially, Brazil has a system of sheep carcass grading regulated by the Ordinance number 307 of December 26, 1990 (Brasil, 1990). Despite using muscularity and fatness traits, the national system is complex, and there are no official records of grading. In this scenario, subjective grading methods can be used to assess, guide the production, and predict meat production.

However, for WSM and PSM, CS and FS were not good predictors, either individually, or in combination. Jones et al. (1993) and Stanford et al. (1997) found that subjective traits can show good prediction results when used in heterogeneous lots of animals. Einarsson et al. (2014) and Rius-Vilarrasa et al. (2009) obtained $\mathrm{R}^{2}$ values of 0.49 and 0.41 , respectively, with the EUROP system for prediction of meat yield and primal cut yield, the same way as in the work of Johansen et al. (2006). As commercial market lambs were used in the current study directly from the slaughterhouse, the demand made by the industry for uniformity in purchased lambs provided a certain homogeneity, which can be seen by the BW variation observed.

Although the results for CS and FS were not satisfactory, these traits were included in the multivariate models generated by the stepwise regression procedure. In the case of WSM, this inclusion indicates certain importance of FS among other traits that were not included in the model, but had relationships with WSM, such as K and Wr (Table 2). Díaz et al. (2004) used the stepwise procedure for multivariate prediction of weight and yield of lean, fat, and bone from lamb carcasses. Likewise, FS was included in the models, in this case, for weight and yield of fat.

With the exception of the measure $G$, the linear measurements of the carcass showed good prediction of WSM, both in the simple regression and as part of the model generated by stepwise regression. These results support the potential of using video image analysis (VIA), which uses prediction equations based on external carcass measurements, for the prediction of meat production (Cunha et al., 2004; Hopkins et al., 2004; Rius-Vilarrasa et al., 2009; Einarsson et al., 2014). Although the perimeter measures have showed relationship with WSM and PSM, the use of these online would be impractical by the method of obtainment, unlike the measurements obtained in the dorsal and lateral images of carcasses, captured in VIA systems.

\section{Conclusions}

The EUROP conformation and fatness scores can be used to predict the weight and percentage of salable meat from market lambs in Brazil. The combination of conformation and fatness with carcass linear measurements increases the accuracy to predict the meat production.

\section{Acknowledgments}

The authors thank Fundação de Amparo à Pesquisa do Estado de São Paulo for the financial support (Project no. 09/15600-8). 


\section{References}

AHDB Beef \& Lamb. 2012. Understanding lambs \& carcases for better returns. Agriculture and Horticulture Development Board, AHDB, Warwickshire, UK.

Beef+ Lamb New Zealand Ltd. 2013. Available at: $<$ http://beeflambnz. com/Global/Microsite/index.html> Accessed on: Mar. 2, 2010.

Brady, A. S.; Belk, K. E.; LeValley, S. B.; Dalsted, N. L.; Scanga, J. A.; Tatum, J. D. and Smith, G. C. 2003. An evaluation of the lamb vision system as a predictor of lamb carcass red meat yield percentage. Journal of Animal Science 81:1488-1498.

Brasil. 1952. Decreto $\mathrm{n}^{\circ} 30.691$, de 29 de março de 1952. Aprova o novo Regulamento da Inspeção Industrial e Sanitária de Produtos de Origem Animal. Diário Oficial da União, Brasília, DF, 7 jul. 1952.

Brasil. 1990. Portaria $\mathrm{n}^{\mathrm{o}}$ 307, de 26 de dezembro de 1990. Aprova o Sistema Nacional de Tipificação de Carcaças Ovinas. Diário Oficial da União, Brasília, DF, 27 dez. 1990.

Brasil. 2008. Instrução Normativa ${ }^{0} 56$, de 6 de novembro de 2008. Estabelecer os procedimentos gerais de Recomendações de Boas Práticas de Bem-Estar para Animais de Produção e de Interesse Econômico - REBEM, abrangendo os sistemas de produção e o transporte. Diário Oficial da União, Brasília, DF, 7 nov. 2008.

Carrasco, S.; Ripoll, G.; Sanz, A.; Álvarez-Rodríguez, J.; Panea, B.; Revilla, R. and Joy, M. 2009. Effect of feeding system on growth and carcass characteristics of Churra Tensina light lambs. Livestock Science 121:56-63.

Commission Regulation (EC) No 823/98. 1998. Commission Regulation (EC) No 823/98 of 20 April 1998 amending Regulation (EEC) No 461/93 laying down detailed rules for the Community scale for the classification of carcases of ovine animals.

Cunha, B. C. N.; Belk, K. E.; Scanga, J. A.; LeValley, S. B.; Tatum, J. D. and Smith, G. C. 2004. Development and validation of equations utilizing lamb vision system output to predict lamb carcass fabrication yields. Journal of Animal Science 82:2069-2076.

Díaz, M. T.; Cañeque, V.; Lauzuruca, S.; Velasco, S.; Ruíz de Huidobro, F. and Pérez, C. 2004. Prediction of suckling lamb carcass composition from objective and subjective carcass measurements. Meat Science 66:895-902.

Einarsson, E.; Eythórsdóttir, E.; Smith, C. R. and Jónmundsson, J. V. 2014. The ability of video image analysis to predict lean meat yield and EUROP score of lamb carcasses. Animal 8:1170-1177.

FAO - Food and Agriculture Organization of the United Nations. 2015. FAOSTAT database. Available at: <http://faostat3.fao.org/ browse/Q/QA/E $>$. Accessed on: Feb. 15, 2016.

Ferraz, J. B. S. and Felício, P. E. 2010. Production systems - An example from Brazil. Meat Science 84:238-243.
Hopkins D. L.; Safari, E.; Thompson, J. M. and Smith, C. R. 2004 Video image analysis in the Australian meat industry - precision and accuracy of predicting lean meat yield in lamb carcasses. Meat Science 67:269-274.

Johansen, J.; Aastveit, A. H.; Egelandsdal, B.; Kvaal, K. and Røe, M. 2006. Validation of the EUROP system for lamb classification in Norway; repeatability and accuracy of visual assessment and prediction of lamb carcass composition. Meat Science 74:497-509.

Jones, S. D. M.; Robertson, W. M. and Price, M. A. 1993. The assessment of saleable meat yield in lamb carcasses. p.190. In: International Congress on Meat Science and Technology, Calgary.

Lambe, N. R.; Navajas, E. A.; Bünger, L.; Fisher, A. V.; Roehe, R. and Simm, G. 2009. Prediction of lamb carcass composition and meat quality using combinations of post-mortem measurements. Meat Science 81:711-719.

Nsoso, S. J.; Young, M. J. and Beatson, P. R. 2000. A review of carcass conformation in sheep: assessment, genetic control and development. Small Ruminant Research 35:89-96.

Price, M. A. 1995. Development of carcass grading and classification systems. p.173-199. In: Quality and grading of carcasses of meat animals. Jones, S. D. M., ed. CRC Press, Boca Raton.

Rius-Vilarrasa, E.; Bünger, L.; Maltin, C.; Matthews, K. R. and Roehe, R. 2009. Evaluation of Video Image Analysis (VIA) technology to predict meat yield of sheep carcasses on-line under UK abattoir conditions. Meat Science 82:94-100.

Russel, A. J. F.; Doney, J. M. and Gunn, R. G. 1969. Subjective assessment of body fat in live sheep. Journal Agriculture Science $72: 451-454$

Safari, E.; Hopkins, D. L. and Fogarty, N. M. 2001. Diverse lamb genotypes 4. Predicting the yield of saleable meat and high value trimmed cuts from carcass measurements. Meat Science 58:207-214.

Smith, G. C.; Carpenter, Z. L. and King, G. T. 1969. Ovine carcass cutability. Journal of Animal Science 29:272-282.

Stanford, K.; Woloschuk, C. M.; McClelland, L. A.; Jones, S. D. M. and Price, M. A. 1997. Comparison of objective external carcass measurements and subjective conformation scores for prediction of lamb carcass quality. Canadian Journal of Animal Science $77: 217-223$

Stanford, K.; Jones, S. D. M. and Price, M. A. 1998. Methods of predicting lamb carcass composition: A review. Small Ruminant Research 29:241-254

Zambrano-Bigiarini, M. 2012. hydroGOF: Goodness-of-fit functions for comparison of simulated and observed hydrological time series. R package version 0.3-5. Available at: $<$ http://CRAN.Rproject.org/package $=$ hydroGOF $>$. Accessed on: Feb. 17, 2016. 